\title{
Mental Health, Well-Being, and Psychological Flexibility in the Stressful Times of the COVID-19 Pandemic
}

\section{OPEN ACCESS}

Edited by:

Claude-Hélène Mayer,

University of Johannesburg,

South Africa

Reviewed by:

Yuke Tien Fong,

Singapore General Hospital,

Singapore

Murat Yildirim

Ağrı ibrahim Çeçen University, Turkey

*Correspondence:

Grażyna Wąsowicz

gwasowicz@kozminski.edu.pl

tORCID:

Grażyna Wasowicz 0000-0003-4769-8963

Szymon Mizak 0000-0003-0308-007X

Jakub Krawiec

0000-0002-8422-8090

Wojciech Białaszek

0000-0002-4672-4376

Specialty section:

This article was submitted to Personality and Social Psychology, a section of the journal

Frontiers in Psychology

Received: 30 December 2020

Accepted: 12 April 2021

Published: 17 May 2021

Citation:

Wąsowicz G, Mizak S, Krawiec J and Białaszek W (2021) Mental Health, Well-Being, and Psychological Flexibility in the Stressful Times of the

COVID-19 Pandemic.

Front. Psychol. 12:647975. doi: 10.3389/fpsyg.2021.647975

\section{Grażyna Wąsowicz ${ }^{1 *}$, Szymon Mizak ${ }^{2 \dagger}$, Jakub Krawiec ${ }^{2 \dagger}$ and Wojciech Białaszek ${ }^{2 \dagger}$}

${ }^{1}$ Department of Economic Psychology, Kozminski University, Warsaw, Poland, ${ }^{2}$ DecisionLab: Center for Behavioral Research in Decision Making, Institute of Psychology, SWPS University of Social Sciences and Humanities, Warsaw, Poland

This study investigated the relationships between selected emotional aspects of mental ill-health (depression, anxiety, and stress, DASS) and mental well-health (well-being) experienced during the COVID-19 pandemic. The theoretical model of the study was based on Martin Seligman's positive psychology and PERMA theory and Paul Wong's Existential Positive Psychology 2.0 Theory, which postulates that negative experiences contribute to well-being and personal growth. The static approach was complemented by exploring the mediating role of psychological flexibility (defined as acceptance and action in the current situation) in the relationship between negative emotions and wellbeing. The data were collected during the initial phase of the COVID-19 pandemic from 277 participants (221 women), aged $M=33.83, \mathrm{SD}=12.77$. The results confirmed that negative emotions correlated negatively with various domains of well-being (PERM), except for accomplishment (completing tasks and fulfill daily responsibilities). Moreover, negative emotions were related to the general well-being through psychological flexibility in that higher depression, anxiety, and stress were associated with lower psychological flexibility, which decreased general well-being. Finally, negative emotions were shown to be beneficial, having an adaptive effect that allows individuals to maintain their ability to cope with the situation, reach goals, and fulfill daily duties and responsibilities despite critical, stressful situation (like the COVID-19 pandemic) that limit their psychological flexibility. This observation confirmed the positive potential of negative aspects of life postulated within Existential Positive Psychology.

Keywords: anxiety, depression, flourishing, mental health, psychological flexibility, stress, well-being

\section{INTRODUCTION}

The study reported in the article was conducted in Poland in April 2020, one month after the first person infected with SARS-CoV-2 (March 4, 2020) was registered. At the beginning of April, the number of confirmed cases in Poland climbed to 2554, and deaths due to the COVID-19 infection reached 43. At the end of this month, the number of confirmed infections in Poland was 12,877, and 644 persons died. At the time of the manuscript revision (April 2021), 2.46 million 
Poles were infected, and 55065 deaths were registered, with 132 million global infections and 2.87 million deaths.

The COVID-19 pandemic poses a serious threat to individuals' well-being (Arslan et al., 2020a; Xiong et al., 2020; Yildırım and Arslan, 2020), and it has caused many people to suffer from mental health problems worldwide (Arslan et al., 2020a; Qiu et al., 2020; Xiong et al., 2020). Recently published reports on the prevalence of depression, anxiety, and stress during the COVID19 pandemic have shown high levels of mental health problems among health workers in Italy (for depression, anxiety, and stress, respectively: 24.73, 19.80, and 21.9\%; Rossi et al., 2020; Y1ldirım and Güler, 2021) and in Spain (46\% in the case of depression, and $58.6 \%$ for anxiety; Luceño-Moreno et al., 2020). In the general Chinese population, $16.5 \%$ of participants reported high levels of depression, $28.8 \%$ reported anxiety, and $8.1 \%$ experienced high stress (Wang et al., 2020; Yildirim and Arslan, 2020). The recent meta-analysis on depression, anxiety, and stress by Salari et al. (2020) confirmed high levels of mental ill-health in $1 / 3$ of researched general populations. The analysis showed high levels of depression in $33.7 \%$ (based on 14 studies), anxiety in $31.9 \%$ (17 studies), and stress in $29.6 \%$ (five studies) of individuals. Therefore, factors that influence mental health and well-being in the times of the COVID-19 pandemic should be identified to support individuals and mental health services providers in their struggle against the negative psychological consequences of living in the stressful time (Tanhan et al., 2020). Arslan et al. (2020a) proposed that mental health consists of mental ill-health and well-health (see also Allen and McKenzie, 2015; Spiker and Hammer, 2019; Arslan and Allen, 2020). The former term refers to emotional states of depression, anxiety, stress, and adjustment problems that worsen optimal functioning, whereas the latter refers to fulfilling emotional, social, and psychological experiences (Arslan et al., 2020b).

In this study, we focused on the relationship between selected emotional aspects of mental ill-health (depression, anxiety, and stress) and mental well-health (well-being). The tripartite model of anxiety and depression (Clark and Watson, 1991; Lovibond and Lovibond, 1995; Brown et al., 1997) served as a theoretical background for the negative emotions investigated in the study. Within the model, depression is related to anhedonia and low or absent positive affect, anxiety is characterized by physiological hyperarousal and fearfulness, and stress is described as negative affect, persistent tension, irritability, and proneness to become upset (Lovibond and Lovibond, 1995; Brown et al., 1997). Concerning the wellbeing concept, we referred to the pillars of positive psychology founded by Martin Seligman, which try to determine the factors "that allow individuals, communities and societies to flourish," experience well-being, and build individual strength (Seligman and Csikszentmihalyi, 2000, p. 5). Flourishing results from the interaction among five elements of well-being, namely, positive emotions, engagement in life, and work, relationships, meaning in life and work, and accomplishment (PERMA theory). Butler and Kern (2016), the authors of the PERMA profiler, defined these well-being dimensions (and the PERMA profiler scales) as follows. The positive emotions dimension refers to the general tendency to feel contentment and joy. Engagement in life and work means being absorbed, interested, and involved. The relationships dimension refers to human motivation to seek and maintain positive relationships, which expresses itself in feeling loved, supported, and valued by others. The meaning in life and work dimension refers to the sense of serving something "bigger" (Seligman, 2010), to a sense of a purposeful and valuable life worth living. The accomplishment dimension refers to the human motivation to achieve and master new skills and the feeling of being able to reach goals, complete tasks, and fulfill daily responsibilities. The PERMA model integrates three types of happiness, hedonic happiness (high positive affect and low negative affect), prudential happiness (engagement in life), and eudaimonic happiness (meaning in life and sense of fulfillment) (Wong, 2011, 2021). The model has been found to predict mental health (Kern et al., 2015; Butler and Kern, 2016).

The data reviewed above show that the COVID-19 pandemic may cause strong negative emotions expressed in depression, anxiety, and stress. Studies have reported negative relations between stress and well-being in various aspects of human life and clinical practice (Schönfeld et al., 2016; Wersebe et al., 2018). Anxiety and depression have also been found to lead to decreased well-being in various contexts (Smalbrugge et al., 2006; Lagnado et al., 2017; Malone and Wachholtz, 2018). Recent studies on the negative emotional states during the COVID-19 pandemic have shown negative correlations of stress (Bono et al., 2020), anxiety, and depression with psychological well-being (Vindegaard and Benros, 2020). However, to the best of the authors' knowledge, no attempts have been made to describe the relationship between the negative emotional states and the well-being in terms of flourishing. To fill this gap, the first objective of this study was to explore the relationship between depression, anxiety, and stress and the five dimensions of flourishing. Based on conclusions from studies on negative emotions and psychological well-being, negative relationships could be expected.

On the other hand, negative emotions have an adaptive function (Nesse, 2019). The acceptance of negative emotions is important for optimal functioning (Stockton et al., 2019; Carreno et al., 2021), and the advantages of negative emotions have been documented in the literature (Calhoun and Tedeschi, 2006; Kashdan and Biswas-Diener, 2014; Ivtzan et al., 2015). Moreover, the Existential Positive Psychology 2.0 (Wong, 2011, 2020) stresses the importance of negative emotions and stressful experiences in individuals' well-being. It postulates that "sustainable flourishing can only be achieved on the foundation of overcoming suffering" (p. 6) and that negative emotions experienced, e.g., in times of crisis, can lead to adaptive benefits, personal growth, and resilience. Since we did not have clear grounds for hypotheses, in the exploration, we limited ourselves to the research question about the existence and direction of relations between the three negative emotional states and the five dimensions of well-being, as defined in the PERMA theory. In particular, we were interested in finding out whether the negative emotional states experienced in the difficult time of the COVID-19 pandemic correlate with psychological benefits and mental well-health.

The traditional psychological approach offers several theories about what determines mental health and well-being. These 
include, e.g., references to (a) the intensity and quantity of positive compared with negative affective states (Diener, 2000; Fredrickson and Losada, 2005), (b) psychological needs of autonomy, competence, and relatedness fulfillment (Deci and Ryan, 2000), meaning in life (Arslan et al., 2020a), and (c) meaningful accomplishment (Csikszentmihalyi, 1990). The static approach taken in the abovementioned theories is criticized for not capturing "the dynamic, fluctuating, and contextuallyspecific behaviors that people deploy when navigating the challenges of daily life" (Kashdan and Rottenberg, 2010, p. 865). In the context of the COVID-19 pandemic, it is of utmost importance to identify psychological strengths that can help individuals overcome depression, stress, and anxiety and maintain well-being. Researchers have confirmed that meaning in life (Arslan et al., 2020a; Carreno et al., 2021; Eisenbeck et al., 2021), hope (Yildırım and Arslan, 2020), positivity (Yıldırım and Güler, 2021), and self-efficacy (Yıldırım and Güler, 2020) positively influence mental health and well-being. They also identified two variables that cover dynamics in coping with adverse situations and relate to mental health and well-being. These are resilience, understood as one's ability to recover from negative events and resist illness (Wong, 2020; Yildirım and Arslan, 2020; Yildirım et al., 2020), and psychological flexibility (Arslan et al., 2020a; Tanhan et al., 2020). We focus on the latter.

The term "psychological flexibility" covers many meanings, like adapting to situational demands, re-configuring mental resources, shifting perspectives, and balancing competing desires, needs, and life domains (Kashdan and Rottenberg, 2010, p. 865). Various facets of flexibility have been studied; however, it is believed that (a) psychological inflexibility and negative emotions correlate positively (Fresco et al., 2006; Tavakoli et al., 2019), (b) anxiety and depression are related to the loss of flexibility (Kashdan and Rottenberg, 2010) and are likely to appear when people need to adjust to changes in their environment (Mitchell et al., 2007; Mitchell et al., 2007; Mesidor and Sly, 2016) while coping flexibility leads to lower anxiety and depression (Cheng and Cheung, 2005), and (c) psychological flexibility has a major contribution to well-being (Kashdan and Rottenberg, 2010; Wersebe et al., 2018).

In the context of mental health threatened by the COVID-19 pandemic, Arslan et al. (2020b) found the relationship between coronavirus stress and psychological inflexibility. Moreover, psychological inflexibility mediated the relationship between coronavirus stress and mental ill-health, which means that negative emotions decreased psychological flexibility that in turn decreased mental well-health. Psychological flexibility measures how a person adapts to fluctuating situational demands (Kashdan and Rottenberg, 2010) and to the extent to which a person accepts the situational demands (Bond et al., 2011). According to Existential Positive Psychology, optimal functioning depends on the acceptance of negative emotions (Wong, 2011; Stockton et al., 2019; Carreno et al., 2021). Therefore, handling negative emotions with lower or higher acceptance and psychological flexibility affects individuals' well-being.

Based on available results, one can generally hypothesize that higher levels of depression, anxiety, and stress decrease psychological flexibility (H1), which mediates the relationship between the negative emotional states and general wellbeing (H2). The psychological (in)flexibility consists of various psychological processes (Tanhan et al., 2020; see also Hayes et al., 2006; Tanhan, 2019), and well-being comprises various dimensions; therefore, we intended to explore the detailed relationships without posing detailed hypotheses, between the three emotional states and five dimensions of well-being and assess the mediating role of flexibility.

\section{METHODS}

\section{Participants}

Three hundred and fifty-eight Poles participated in the study. To the methodological correctness, we excluded data from nonadults, those infected with the COVID-19, and those undergoing psychiatric treatment. The analyses were conducted on a sample of 277 participants (221 females and 56 males) aged 19$82(M=33.83, \mathrm{SD}=12.77)$. In the sample, $26 \%$ reported socioeconomic status higher than the average, $5.1 \%$ lower than average, and $69 \%$ claimed a medium status. The households consisted of one to nine members. The study presented here was a part of a larger project, and the goal was to obtain a broad and diverse research sample. No a priori power analysis was conducted. As an reviewer suggested, an a posteriori power analysis was conducted using a Monte Carlo power analysis for the indirect effects with a bootstrapped confidence interval. The analysis showed that for the collected sample, the power was 0.88 when assuming a small effect size $(r=0.25)$, which was appropriate for mediation analyses (Schoemann et al., 2017).

\section{Procedure}

Participants were recruited by email and through social media (Facebook) from students and their social contacts using convenient sampling. The sample selection was not randomized. The study was conducted in accordance with the Declaration of Helsinki. Participation in the study was anonymous and voluntary, and the responses were confidential. Participants provided informed consent, which informed them that they could withdraw from the study at any time. They completed (in Polish) a series of questionnaires via the Google Forms platform, following all necessary demographic information, such as age, gender, place of residence, number of people in the household, and marital status. The participants also answered questions about their profession, the number and type of safety behaviors against infection, participation in psychiatric treatment, and socioeconomic status. On average, the procedure lasted about $20 \mathrm{~min}$. Participants did not receive any incentives.

\section{Instruments}

In this article, we present part of the study that used the following instruments.

PERMA profiler is a multidimensional scale that measures five domains of well-being, positive emotions, engagement, relationships, meaning, and accomplishment, with three items each (Butler and Kern, 2016). The total score for these domains constitutes a total measure of well-being. Participants expressed 
their answers on a Likert scale from $0=$ not at all to $6=$ completely (instead of the original 1 to 10 , to be consistent with the other questionnaires in the entire set; see Dawes, 2008). The Cronbach's alpha was 0.92 for the well-being measure overall, and 0.85 for positive emotions, 0.64 for engagement, 0.83 for relationships, 0.92 for meaning, and 0.80 for accomplishment subscales.

Acceptance and Action Scale (AAQ-II; Bond et al., 2011). The scale consists of seven statements measuring psychological flexibility. The participants assessed each statement on a 7-point scale (from 1 = "never true" to 7 = "always true"). The higher the overall score, the lower psychological flexibility (lower acceptance and action). For the study, we used the Polish version of the instrument (Kleszcz et al., 2018). The value of Cronbach's alpha in the current study was 0.91 .

The Depression, Anxiety, and Stress Scale (DASS-21; Lovibond and Lovibond, 1996; Brown et al., 1997) is a set of three self-reported scales and consists of 21 items assessing the symptoms of depression, anxiety, and stress experienced during the last week (in our study) on a 4-point scale ranging from 0 (did not apply to me at all) to 3 (applied to me very much, or most of the time). The scales provide three separate scores. Higher scores indicate more frequent symptoms of depression, anxiety, and stress. Cronbach's alphas in our study were $0.91,0.87$, and 0.88 for each scale, respectively.

For this study, the first author adapted PERMA and DASS21 scales to Polish, following the backtranslation procedure. The structure of the measures was confirmed in CFA (for PERMA: $\chi^{2}=318.06, p<0.001$, for DASS-21 $\left.\chi^{2}=683.56, p<0.001\right)$. Goodness of fit indices showed acceptable values (for PERMA: CFI $>0.91$, for DASS-21: CFI > 0.86).

\section{Data Analysis}

The data analysis was conducted using SPSS and PROCESS MACRO for SPSS (Hayes, 2017). The mediation analysis was chosen based on the theoretical status of psychological flexibility described in the introduction. We used bootstrapping procedures to test the significance of the mediation effects (5000 bootstrapped samples and 95\% confidence intervals). These procedures were performed separately for each mediation analysis (not within a single model). The mediation model is depicted in Figure 1. The descriptive statistics (means and

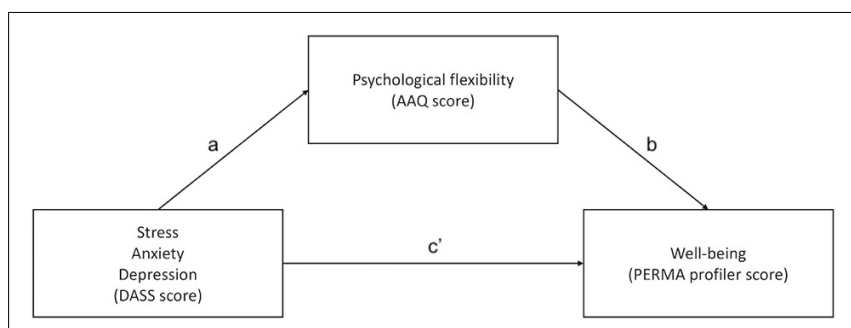

FIGURE 1 | Model depicting the mediation of psychological flexibility on the relationship between negative emotions and well-being. Note: Paths $a$ and $b$ constitute the indirect effect, and path $c^{\prime}$ the direct effect. The sum of all paths represents the total effect exerted on the dependent variable. standard deviations) of all the measured variables are presented in Table 1.

\section{RESULTS}

In the first stage of the analyses, Pearson's product-moment correlation coefficients were calculated to explore the relations between emotional scales (DASS-21) and well-being scales (PERMA, see Table 2). As expected, the relationships (from weak to strong) of depression, anxiety, and stress with the general wellbeing and most of the PERMA subscales were negative. However, a positive, strong relationship emerged between the DASS scales and the accomplishment scale.

In the second stage, a two-step analysis was carried out to explore the relationship between well-being scales (PERMA), emotional scales (DASS-21), and psychological flexibility (AAQII scale). A partial correlation between emotional scales and well-being was calculated in the first step while controlling for psychological flexibility (Table 3). The results showed that when controlling for the psychological flexibility, the relation of anxiety and stress with general well-being and some of its subscales disappeared. Moreover, the relations between depression and general well-being and its subscales were weaker, but the signs of the relations remained the same (compared to the results presented in Table 2).

In the next step, we examined the mediating role of psychological flexibility in the relation between the DASS-21 and PERMA profiler scales. The mediation analysis showed a series of significant mediation effects (Table 4). In all cases, the path a between DASS-21 scales and AAQ score was significant (all ps $<0.001$ ), and the coefficients were greater than zero (all estimates $>0$ ), indicating a direct relationship between negative emotions and psychological flexibility. Specifically, when negative emotions increased, people tended to manifest lower psychological flexibility. The result supported H1. Moreover, psychological flexibility was a significant mediator of the relationship between all the DASS-21 subscales and the overall PERMA profiler score, supporting H2. For stress and anxiety, full mediation effects occurred, while in the case of depression, the mediation effect explained only part of the relationship.

All mediation analyses (except for depression and engagement) revealed significant indirect full or partial effects of the positive emotions, engagement, relationships, and meaning subscales of PERMA (all ps $<0.001$ for indirect effects). The pattern of results was the same as described for the general PERMA score: depression, anxiety, and stress were negatively related to the well-being dimensions (estimates $<0$ for all direct effects) and positively related to AAQ-II score (all estimates $>0$ for path a of indirect effect), with the latter associated with lower well-being (all estimates $<0$ for path $b$ of indirect effects). However, in the case of the accomplishment scale, the pattern of results was reversed. The AAQ-II score also mediated the relationship between the DASS-21 scales and the accomplishment scale (which were positively related with all estimates of direct effects $>0$ ). Furthermore, negative emotions were associated with lower 
TABLE 1 | Descriptive statistics and distribution diagnostics for variables used in analyses.

\begin{tabular}{|c|c|c|c|c|c|c|c|c|c|c|}
\hline & PERMA PE & PERMA E & PERMA R & PERMA M & PERMA A & PERMA OA & AAQ & DASS S & DASS A & DASS D \\
\hline Mean & 11.88 & 13.20 & 12.98 & 12.72 & 8.54 & 62.87 & 21.02 & 15.81 & 7.83 & 10.86 \\
\hline SD & 3.19 & 2.97 & 3.73 & 3.94 & 3.55 & 13.44 & 9.32 & 10.67 & 9.28 & 10.67 \\
\hline Skewness & -0.75 & -0.79 & -0.81 & -0.87 & 0.41 & -0.79 & 0.58 & 0.48 & 1.63 & 1.15 \\
\hline Kurtosis & 0.25 & 0.64 & 0.05 & 0.56 & -0.57 & 0.52 & -0.28 & -0.62 & 2.41 & 0.59 \\
\hline Minimum & 1.00 & 2.00 & 2.00 & 0.00 & 2.00 & 16.00 & - & 0.00 & 0.00 & 0.00 \\
\hline Maximum & 18.00 & 18.00 & 18.00 & 18.00 & 18.00 & 88.00 & - & 42.00 & 42.00 & 42.00 \\
\hline
\end{tabular}

psychological flexibility (path a estimates $>0$ ), and lower psychological flexibility was associated with a stronger feeling of being able to complete tasks and daily responsibilities (path b estimates $>0$ ).

\section{DISCUSSION}

In the study, we examined depression, anxiety, and stress experienced in the times of the COVID-19 pandemic and their relations with well-being. As expected, the results showed that negative emotions were negatively related to various domains of well-being (positive emotions, engagement, relationships, and meaning). We also observed positive relations between negative emotions and the accomplishment dimension of well-being. The accomplishment dimension refers to human motivation to achieve and master different skills, reach goals, complete tasks, and fulfill daily responsibilities; therefore, it reflects positive aspects of human functioning. The positive relationship between negative emotions and this dimension of well-being is consistent with the premise of Existential Positive Psychology, which postulates positive psychological benefits of negative, stressful aspects of life (Wong, 2011, 2020; Ivtzan et al., 2015).

In the study, we also found that higher depression, anxiety and stress were associated with lower psychological flexibility, defined as acceptance and action in a current situation. The results confirmed $\mathrm{H} 1$ and outcomes reported by other researchers, who showed that negative emotions are related to the loss of psychological flexibility. This observation is relevant to times before the pandemic (Kashdan and Rottenberg, 2010; Tavakoli et al., 2019) and during the pandemic (current study), suggesting that the relationship between negative emotions and psychological flexibility is universal. In the study, we also tested the mediating role of psychological flexibility in the relationship between negative emotions and well-being. We found that (a) depression, anxiety, and stress were related to the general well-being through psychological flexibility (H2 confirmed), and (b) lower acceptance and action (lower psychological flexibility) were associated with lower general wellbeing.

One new and interesting result referred to the relationship between negative emotions and the accomplishment dimension of well-being mediated by psychological flexibility. In everyday life situations, it is useful to seek psychological flexibility, benefits of which (just as the costs of psychological inflexibility) are well documented in the literature (Kashdan and Rottenberg, 2010).
Moreover, psychological flexibility is seen as a protective factor against difficult situations (Masuda et al., 2010; Meyer et al., 2013; Kleszcz et al., 2018). The results of our study showed that negative emotions might decrease psychological flexibility, and although this lower psychological flexibility may reduce the general well-being, it also may give individuals a better sense of coping with a difficult situation by completing tasks and fulfilling daily responsibilities. In other words, negative emotions may be beneficial, having an adaptive effect that allows individuals to cope with the situation, reach goals, and fulfill daily duties and responsibilities despite the critical, stressful situations (like the COVID-19 pandemic) that limit their psychological flexibility. This observation confirms the positive potential of negative aspects of life postulated by Existential Positive Psychology (Wong, 2011, 2020; Ivtzan et al., 2015).

\section{Limitations and Implications}

Due to the homogeneity of the sample (Polish participants), the generalizability of the results and external validity of the study are limited. However, the results suggest the importance of psychological flexibility for mental

TABLE 2 | Pearson correlations between the results of the DASS-21 and PERMA scales.

\begin{tabular}{lccc}
\hline & Depression & Anxiety & Stress \\
\hline Positive emotions & $-0.61^{\star \star \star}$ & $-0.37^{\star \star \star}$ & $-0.47^{\star \star \star}$ \\
Engagement & $-0.40^{\star \star \star}$ & $-0.17^{\star \star}$ & $-0.21^{\star \star \star}$ \\
Relations & $-0.38^{\star \star \star}$ & $-0.15^{\star}$ & $-0.19^{\star \star}$ \\
Meaning & $-0.55^{\star \star \star}$ & $-0.27^{\star \star \star}$ & $-0.36^{\star \star \star}$ \\
Accomplishment & $0.56^{\star \star \star}$ & $0.52^{\star \star \star}$ & $0.64^{\star \star \star}$ \\
Well-being & $-0.60^{\star \star \star}$ & $-0.30^{\star \star \star}$ & $-0.37^{\star \star \star}$ \\
\hline
\end{tabular}

${ }^{*} p<0.05,{ }^{* *} p<0.01,{ }^{* * *} p<0.001$.

TABLE 3 | Partial correlations between the results of the DASS and PERMA scales when controlling for psychological flexibility.

\begin{tabular}{lccc}
\hline & Depression & Anxiety & Stress \\
\hline Positive emotions & $-0.43^{\star \star \star}$ & $-0.14^{\star}$ & $-0.23^{\star \star \star}$ \\
Engagement & $-0.31^{\star \star \star}$ & -0.03 & -0.07 \\
Relations & $-0.17^{\star \star}$ & 0.09 & 0.09 \\
Meaning & $-0.32^{\star \star \star}$ & 0.03 & -0.04 \\
Accomplishment & $0.32^{\star \star \star}$ & $0.31^{\star \star \star}$ & $0.44^{\star \star \star}$ \\
Well-being & $-0.40^{\star \star \star}$ & -0.02 & -0.06 \\
\hline
\end{tabular}

${ }^{*} p<0.05,{ }^{* *} p<0.01,{ }^{* * *} p<0.001$. 
health in times of pandemic. Mental health professionals psychological strength by increasing psychological utilizing Acceptance and Commitment Therapy (ACT) flexibility (Stockton et al., 2019; Arslan et al., 2020b; could consider these results to help their clients build Tanhan et al., 2020).

TABLE 4 | The mediating effects of psychological flexibility on the relationship between the DASS-21 and PERMA profiler scales.

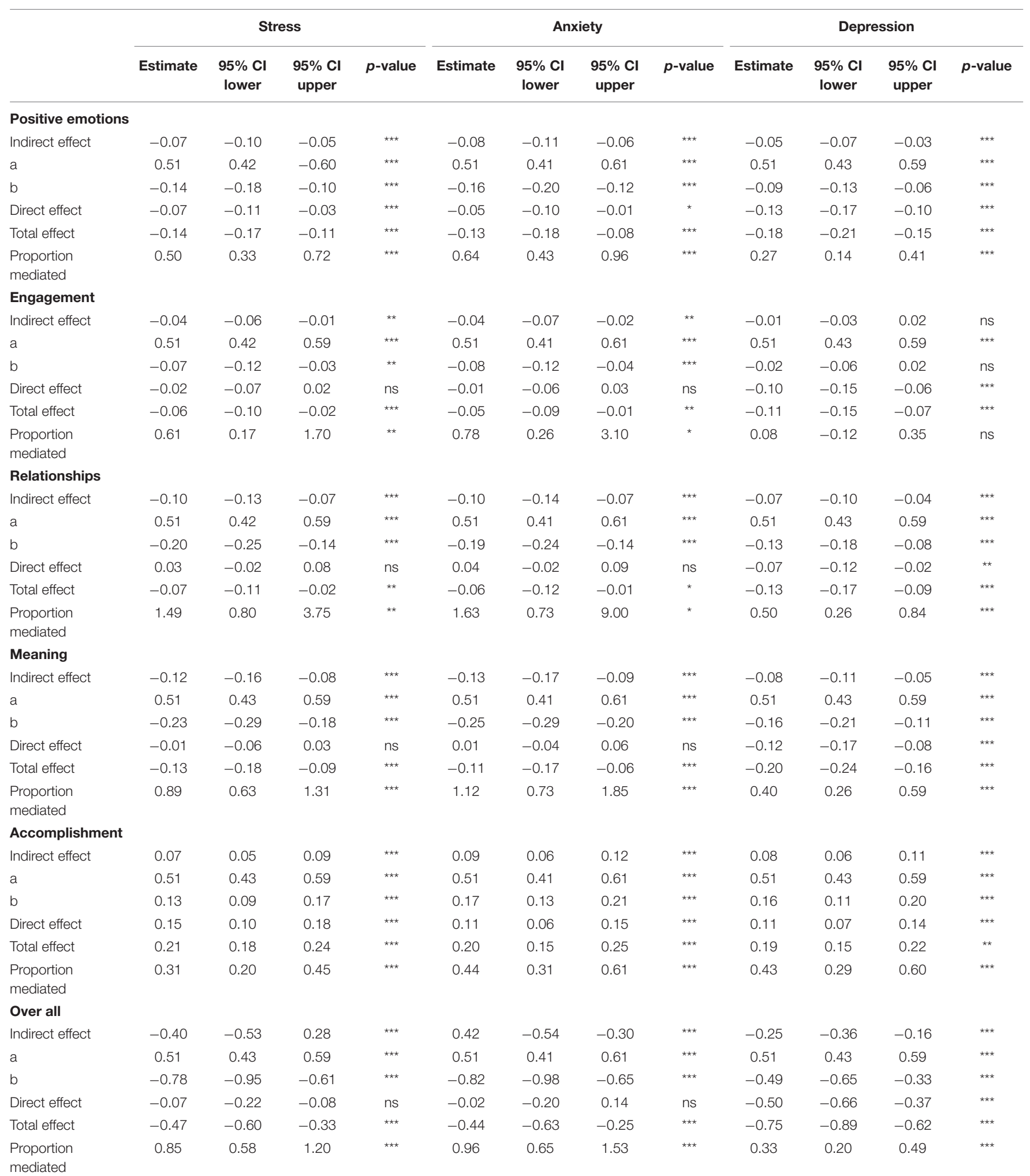


Future research should verify the mediating role of psychological flexibility in the relationship between negative emotions and well-being in a longitudinal study and under different circumstances not affected by the COVID-19 pandemic. Especially, it is important to explore whether the mediating role of psychological flexibility in the relationship between the negative emotions and the accomplishment dimension of well-being reveals a universal pattern.

\section{DATA AVAILABILITY STATEMENT}

The raw data supporting the conclusions of this article will be made available by the authors, without undue reservation.

\section{ETHICS STATEMENT}

The studies involving human participants were reviewed and approved by the Ethics Committee, Kozminski University. The patients/participants provided their written informed consent to participate in this study.

\section{REFERENCES}

Allen, K. A., and McKenzie, V. L. (2015). Adolescent mental health in an Australian contextand future interventions. Int. J. Ment. Health 44, 80-93. doi: 10.1080/ 00207411.2015.1009780

Arslan, G., and Allen, K. A. (2020). Complete mental health in elementary school children: understanding youth school functioning and adjustment. Curr. Psychol. doi: 10.1007/s12144-020-00628-0 [Epub ahead of print].

Arslan, G., Yıldırım, M., Karataş, Z., Kabasakal, Z., and Kılınç, M. (2020a). Meaningful living to promote complete mental health among university students in the context of the COVID-19 Pandemic. Int. J. Ment. Health Addiction doi: 10.1007/s11469-020-00416-8 [Epub ahead of print].

Arslan, G., Yıldırım, M., Tanhan, A., Buluş, M., and Allen, K. A. (2020b). Coronavirus stress, optimism-pessimism, psychological inflexibility, and psychological health: psychometric properties of the Coronavirus stress measure. Int. J. Ment. Health Addiction doi: 10.1007/s11469-020-00337-6 [Epub ahead of print].

Bond, F. W., Hayes, S. C., Baer, R. A., Carpenter, K. M., Guenole, N., Orcutt, H. K., et al. (2011). Preliminary psychometric properties of the acceptance and action questionnaire-II: a revised measure of psychological inflexibility and experiential avoidance. Behav. Ther. 42, 676-688. doi: 10.1016/j.beth.2011.03. 007

Bono, G., Reil, K., and Hescox, J. (2020). Stress and wellbeing in college students during the COVID-19 pandemic: can grit and gratitude help? Int. J. Wellbeing. 10, 39-57. doi: 10.5502/ijw.v10i3.1331

Brown, T. A., Chorpita, B. F., Korotitsch, W., and Barlow, D. H. (1997). Psychometric properties of the Depression Anxiety Stress Scales (DASS) in clinical samples. Behav. Res. Ther. 35, 79-89. doi: 10.1016/s0005-7967(96) 00068- $\mathrm{x}$

Butler, J., and Kern, M. L. (2016). The PERMA-Profiler: a brief multidimensional measure of flourishing. Int. J. Wellbeing 6, 1-48. doi: 10.5502/ijw. v6i3.526

Calhoun, L. G., and Tedeschi, R. G. (2006). "The foundations of posttraumatic growth: anexpanded framework," in Handbook of Posttraumatic Growth:

\section{AUTHOR CONTRIBUTIONS}

GW contributed to the manuscript by theoretical framing, coordinating the data collection, and manuscript writing. WB, SM, and JK conducted the analyses. GW, WB, SM, and JK wrote the first version of the manuscript. All authors revised the manuscript for important intellectual content and approved the final version to be published.

\section{FUNDING}

The study has been supported by internal funds of Kozminski University.

\section{ACKNOWLEDGMENTS}

The authors wish to thank Nikolett Eisenbeck and David Carreno for inspiring data collection in the international study on psychological coping in the times of pandemic and the reviewers for their input. The authors are also grateful to Polish students who supported the data collection process.

Research and Practice, eds L. G. Calhoun and R. G. Tedeschi (Mahwah, NJ: Lawrence Erlbaum Associates Publishers), 3-23.

Carreno, D. F., Eisenbeck, N., Pérez-Escobar, J. A., and García-Montes, J. M. (2021). Inner harmony as an essential facet of well-being: a multinational study during the COVID-19 pandemic. Front. Psychol. 12:648280. doi: 10.3389/fpsyg. 2021.648280

Cheng, C., and Cheung, M. W. (2005). Cognitive processes underlying coping flexibility: differentiation and integration. J. Pers. 73, 859-886. doi: 10.1111/ j.1467-6494.2005.00331.x

Clark, L. A., and Watson, D. (1991). Tripartite model of anxiety and depression: psychometric evidence and taxonomic implications. J. Abnorm. Psychol. 100, 316-336. doi: 10.1037/0021-843x.100.3.316

Csikszentmihalyi, M. (1990). Flow: The Psychology of Optimal Experience. New York, NY: Harper and Row.

Dawes, J. (2008). Do data characteristics change according to the number of scale points used? An experiment using 5-point, 7-point and 10point scales. Int. J. Mark. Res. 50, 61-104. doi: 10.1177/1470785308050 00106

Deci, E. L., and Ryan, R. M. (2000). The "what" and "why" of goal pursuits: human needs and the self-determination of behavior. Psychol. Inq. 11, 227-268. doi: 10.1207/s15327965pli1104_01

Diener, E. (2000). Subjective well-being: the science of happiness and a proposal for a national index. Am. Psychol. 55, 34-43.

Eisenbeck, N., Pérez-Escobar, J. A., and Carreno, D. F. (2021). Meaning-centered coping in the era of COVID-19: direct and moderating effects on depression. Anxiety Stress. Front. Psychol. 12:648383. doi: 10.3389/fpsyg.2021.648383

Fredrickson, B. L., and Losada, M. F. (2005). Positive affect and the complex dynamics of human flourishing. Am. Psychol. 60, 678-686. doi: 10.1037/0003066x.60.7.678

Fresco, D. A., Williams, N. L., and Nugent, N. (2006). Flexibility and negative affect: examining the associations of explanatory flexibility and coping flexibility to each other and to depression and anxiety. Cognit. Ther. Res. 30, 201-210. doi: 10.1007/s10608-006-9019-8

Hayes, A. F. (2017). Introduction to Mediation, Moderation, and Conditional Process Analysis: A Regression-Based Approach. New York, NY: Guilford Publications. 
Hayes, S. C., Luoma, J. B., Bond, F. W., Masuda, A., and Lillis, J. (2006). Acceptance and commitment therapy: model, processes and outcomes. Behav. Res. Ther. 44, 1-25. doi: 10.1016/j.brat.2005.06.006

Ivtzan, I., Lomas, T., Hefferon, K., and Worth, P. (2015). Second Wave Positive Psychology: Embracing the Dark Side of Life. London: Routledge.

Kashdan, T., and Biswas-Diener, R. (2014). The Upside of Your Dark Side: Why Being YourWhole Self-Not Just Your "Good" Self-Drives Success and Fulfillment. New York, NY: Penguin.

Kashdan, T., and Rottenberg, J. (2010). Psychological flexibility as a fundamental aspect of health. Clinic. Psychol. Rev. 30, 865-878. doi: 10.1016/j.cpr.2010.03. 001

Kern, M. L., Waters, L. E., Adler, A., and White, M. A. (2015). A multidimensional approach to measuring well-being in students: application of the PERMA framework. J. Positive Psychol. 10, 262-271. doi: 10.1080/17439760.2014. 936962

Kleszcz, B., Dudek, J. E., Białaszek, W., Ostaszewski, P., and Bond, F. W. (2018). Właściwości psychometryczne polskiej wersji kwestionariusza akceptacji i działania (AAQ-II). Studia Psychologiczne 56, 1-20.

Lagnado, A. M., Gilchrist, K., Cvancarova Smastuen, M., and Memon, A. (2017). Is subjective wellbeing associated with depression. A cross-sectional survey in southeast England. Eur. J. Public Health 27:ckx187.719. doi: 10.1093/eurpub/ ckx187.719

Lovibond, P. F., and Lovibond, S. H. (1995). The structure of negative emotional states: comparison of the Depression Anxiety Stress Scales (DASS) with the Beck depression and anxiety inventories. Behav. Res. Ther. 33, 335-342. doi: 10.1016/0005-7967(94)00075-u

Lovibond, S. H., and Lovibond, P. F. (1996). Manual for the Depression Anxiety Stress Scales. Sydney, N.S.W: Psychology Foundation of Australia.

Luceño-Moreno, L., Talavera-Velasco, B., García-Albuerne, Y., and Martín-García, J. (2020). Symptoms of posttraumatic stress, anxiety, depression, levels of resilience and burnout in Spanish health personnel during the COVID-19 pandemic. Int. J. Environ. Res. and Public Health. 17, 5514. doi: 10.3390/ ijerph17155514

Malone, C., and Wachholtz, A. (2018). The relationship of anxiety and depression to subjective well-being in a Mainland Chinese sample. J. Relig. Health. 57, 266-278. doi: 10.1007/s10943-017-0447-4

Masuda, A., Price, M., Anderson, P. L., and Wendell, J. W. (2010). Disordered eating-related cognition and psychological flexibility as predictors of psychological health among college students. Behav. Modif. 34, 3-15. doi: $10.1177 / 0145445509351569$

Mesidor, J. K., and Sly, K. F. (2016). Factors that contribute to the adjustment of international students. J. Int. Stud. 6, 262-282. doi: 10.32674/jis.v6i1.569

Meyer, E. C., Morissette, S. B., Kimbrel, N. A., Kruse, M. I., and Gulliver, S. B. (2013). Acceptance and action questionnaire-II scores as a predictor of posttraumatic stress disorder symptoms among war veterans. Psychol. Trauma 5, 521-528. doi: 10.1037/a0030178

Mitchell, S., Greenwood, A. K., and Gulielmi, M. C. (2007). Utilization of counselling services: comparing international and U.S. college students. J. Coll. Counse. 10, 117-130. doi: 10.1002/j.2161-1882.2007.tb00012.x

Nesse, R. M. (2019). Good Reasons for Bad Feelings: Insights From the Frontier of EvolutionaryPsychiatry. New York, NY: Dutton.

Qiu, J., Shen, B., Zhao, M., Wang, Z., Xie, B., and Xu, Y. (2020). A nationwide survey of psychological distress among Chinese people in the COVID-19 epidemic: implications and policy recommendations. Gen. Psych. 33:e100213. doi: 10.1136/gpsych-2020-100213

Rossi, R., Socci, V., Pacitti, F., Di Lorenzo, G., Di Marco, A., Siracusano, A., et al. (2020). Mental health outcomes among front-line and second-line health workers during coronavirus disease 2019 (COVID-19) pandemic in Italy. JAMA Networks Open 3, e2010185. doi: 10.1001/jamanetworkopen.2020. 10185

Salari, N., Hosseinian-Far, A., Jalali, R., Vaisi-Raygani, A., Rasoulpoor, S., Mohammadi, M., et al. (2020). Prevalence of stress, anxiety, depression among the general population during the COVID-19 pandemic: a systematic review and meta-analysis. Glob. Health. 16:57. doi: 10.1186/s12992-02000589-w
Schoemann, A. M., Boulton, A. J., and Short, S. D. (2017). Determining power and sample size for simple and complex mediation models. Soc. Psychol. Person. Sci. 8, 379-386. doi: 10.1177/1948550617715068

Schönfeld, P., Brailovskaia, J., Bieda, A., Zhang, X. C., and Margraf, J. (2016). The effects of daily stress on positive and negative mental health: mediation through self-efficacy. Int. J. Clin. Health Psychol. 16, 1-10. doi: 10.1016/j.ijchp.2015.08. 005

Seligman, M. E., and Csikszentmihalyi, M. (2000). Positive psychology. An introduction. Am. Psychol. 55, 5-14. doi: 10.1037//0003-066x.55.1.5

Seligman, M. E. P. (2010). Flourish: Positive Psychology and Positive Interventions. The Tanner Lectures on Human Values Delivered at $e$ University of Michigan October 7, 2010. Available online at: https: //esterlianawati.files.wordpress.com/2018/09/flourish-martin-seligman.pdf (accessed December 20, 2020).

Smalbrugge, M., Pot, A. M., Jongenelis, L., Gundy, C. M., Beekman, A. T. F., and Eefsting, J. A. (2006). The impact of depression and anxiety on well-being, disability and use of health services in nursing home patients. Int. J. Geriatr. Psychiatry. 21, 325-332. doi: 10.1002/gps.1466

Spiker, D. A., and Hammer, J. H. (2019). Mental health literacy as theory: current challenges and future directions. J. Ment Health. 28, 238-242. doi: 10.1080/ 09638237.2018.1437613

Stockton, D., Kellett, S., Berrios, R., Sirois, F., Wilkinson, N., et al. (2019). Identifying the underlying mechanisms of change during acceptance and commitment therapy (ACT): a systematic review of contemporary mediation studies. Behav. Cogn. Psychother. 47, 332-362. doi: $10.1017 /$ S1352465818000553

Tanhan, A. (2019). Acceptance and commitment therapy with ecological systems theory: addressing muslim mental health issues and wellbeing. J. Posit. Psychol. Wellbeing. 3, 197-219. doi: 10.47602/jpsp.v3i2.172

Tanhan, A., Yavuz, K. F., Young, J. S., Nalbant, A., Arslan, G., Yıldırım, M., et al. (2020). A proposed framework based on literature review of online contextual mental health services to enhance wellbeing and address psychopathology during covid-19. Electron. J. Gen. Med. 17:254. doi: 10.29333/ejgm/8316

Tavakoli, N., Broyles, A., Reid, E. K., Sandoval, J. R., and Correa-Fernández, V. (2019). Psychological inflexibility as it relates to stress, worry, generalized anxiety, and somatization in an ethnically diverse sample of college students. J. Contextual Behav. Sci. 11, 1-5. doi: 10.1016/j.jcbs.2018.11.001

Vindegaard, N., and Benros, M. E. (2020). COVID-19 pandemic and mental health consequences: systematic review of the current evidence. Brain. Behav. Immun. 89, 531-542. doi: 10.1016/j.bbi.2020.05.048

Wang, C., Pan, R., Wan, X., Tan, Y., Xu, L., McIntyre, R. S., et al. (2020). A longitudinal study on the mental health of general population during the COVID-19 epidemic in China. Brain. Behav. Immun. 87, 40-48. doi: 10.1016/j. bbi.2020.04.028

Wersebe, H., Lieb, R., Meyer, A. H., Hofer, P., and Gloster, A. T. (2018). The link between stress, well-being, and psychological flexibility during an acceptance and commitment therapy self-help intervention. Int. J. Clin. Health Psychol. 18, 60-68. doi: 10.1016/j.ijchp.2017.09.002

Wong, P. T. (2021). What is Existential Positive Psychology (PP 2.0)? Why is it necessary for mental health during the pandemic? Editorial. Int. J. Existential Positive Psychol. 10,

Wong, P. T. P. (2011). Positive psychology 2.0: towards a balanced interactive model of the good life. Can. Psychol. (Psychologie Canadienne) 52:69. doi: $10.1037 / \mathrm{a} 0022511$

Wong, P. T. P. (2020). Made for Resilience and Happiness: Effective Coping with COVID-19 according to Viktor E. Frankl and Paul T. P. Wong. INPM Press. ISBN 978-1-7987695-2-3. Oakland CA: INPM Press.

Xiong, J., Lipsitz, O., Nasri, F., Lui, L. M. W., Gill, H., Phan, L., et al. (2020). Impact of COVID-19 pandemic on mental health in the general population: a systematic review. J. Affect. Disord. 1, 55-64. doi: 10.1016/j.jad.2020. 08.001

Yıldırım, M., and Arslan, G. (2020). Exploring the associations between resilience, dispositional hope, preventive behaviours, subjective well-being, and psychological health among adults during early stage of COVID-19. Curr. Psychol. doi: 10.1007/s12144-020-01177-2 [Epub ahead of print]. 
Yıldırım, M., Arslan, G., and Özaslan, A. (2020). Perceived risk and mental health problems among healthcare professionals during COVID-19 pandemic: exploring the mediating effects of resilience and coronavirus fear. Int. J. Ment. Health Addiction doi: 10.1007/s11469-020-00424-8 [Epub ahead of print].

Yıldırım, M., and Güler, A. (2020). COVID-19 severity, self-efficacy, knowledge, preventive behaviors, and mental health in Turkey. Death Studies doi: 10.1080/ 07481187.2020.1793434 [Epub ahead of print].

Yıldırım, M., and Güler, A. (2021). Positivity explains how COVID-19 perceived risk increases death distress and reduces happiness. Pers.Individ. Differ. 168:110347. doi: 10.1016/j.paid.2020.110347
Conflict of Interest: The authors declare that the research was conducted in the absence of any commercial or financial relationships that could be construed as a potential conflict of interest.

Copyright (c) 2021 Wasowicz, Mizak, Krawiec and Białaszek. This is an open-access article distributed under the terms of the Creative Commons Attribution License (CC BY). The use, distribution or reproduction in other forums is permitted, provided the original author(s) and the copyright owner(s) are credited and that the original publication in this journal is cited, in accordance with accepted academic practice. No use, distribution or reproduction is permitted which does not comply with these terms. 